\title{
Correction to: Efficient cooperative multicarrier underwater acoustic communication over the Persian Gulf channel
}

\author{
Abdollah Doosti-Aref ${ }^{1} \cdot$ Ataollah Ebrahimzadeh $^{1} \cdot$ Seyed Mehdi Hosseini Andargoli ${ }^{1}$
}

Published online: 31 October 2017

(C) Springer Science+Business Media, LLC 2017

\section{Correction to: Wireless Netw \\ DOI 10.1007/s11276-016-1404-y}

The original version of this article unfortunately contained a mistake in the author group, where Dr. Seyed Mehdi Hosseini Andargoli was not included as a co-author of the article. The correct list of authors has been published with this erratum.

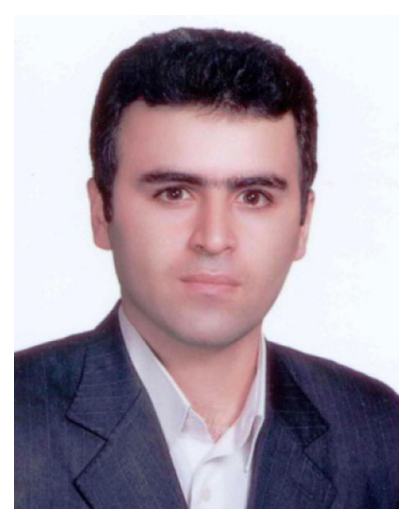

Seyed Mehdi Hosseini Andargoli received B.Sc degree in electronics engineering from Shahed university, Tehran, Iran, in 2004, the M.Sc. and Ph.D. degree in telecommunication systems engineering from $\mathrm{K}$. N. Toosi university of technology, Tehran, Iran, in 2006 and 2011 , respectively. He is currently an assistant professor with department of electrical and computer engineering, Babol Noshirvani university of technology, Babol, Iran. His research interests include resource allocation of cellular networks, cognitive radio networks, sensor networks, optimization and signal processing.
The online version of the original article can be found under doi:10.1007/s11276-016-1404-y.

Abdollah Doosti-Aref a.doosti@stu.nit.ac.ir

Ataollah Ebrahimzadeh e_zadeh@nit.ac.ir

Seyed Mehdi Hosseini Andargoli smh_andargoli@nit.ac.ir

1 Faculty of Electrical and Computer Engineering, Babol Noshirvani University of Technology, Babol, Iran 